\title{
Characterization of hair-follicle side population cells in mouse epidermis and skin tumors
}

\author{
SUN HYE KIM ${ }^{1 *}$, CHRISTOPHER SISTRUNK ${ }^{2 *}$, PAULA L. MILIANI DE MARVAL ${ }^{3}$ \\ and MARCELO L. RODRIGUEZ-PUEBLA ${ }^{3}$
}

\begin{abstract}
${ }^{1}$ Department of Biochemistry, University of Lausanne, CH-1015 Lausanne, Switzerland; ${ }^{2}$ Department of Population Sciences, City of Hope, Duarte, CA 91010; ${ }^{3}$ Department of Molecular Biomedical Sciences, The Center for Human Health and the Environment, and The Comparative Medicine Institute, North Carolina State University, Raleigh,
\end{abstract}

NC 27607, USA

Received March 15, 2017; Accepted September 5, 2017

DOI: $10.3892 / 01.2017 .7048$

\begin{abstract}
A subset of cells, termed side-population (SP), which have the ability to efflux Hoeschst 33342, have previously been demonstrated to act as a potential method to isolate stem cells. Numerous stem/progenitor cells have been localized in different regions of the mouse hair follicle (HF). The present study identified a SP in the mouse HF expressing the ABCG2 transporter and MTS24 surface marker. These cells are restricted to the upper isthmus of the HF and have previously been described as progenitor cells. Consistent with their SP characteristic, they demonstrated elevated expression of ABCG2 transporter, which participates in the dye efflux. Analysis of tumor epidermal cell lines revealed a correlation between the number of SP keratinocytes and the grade of malignancy, suggesting that the SP may play a role in malignant progression. Consistent with this idea, the present study observed an increased number of cells expressing ABCG2 and MTS24 in chemically induced skin tumors and skin tumor cell lines. This SP does not express the CD34 surface marker detected in the multipotent stem cells of the bulge region of the HF, which have been defined as tumor initiation cells. The present study concluded that a SP with properties of progenitor cells is localized in the upper isthmus of the HF and is important in mouse skin tumor progression.
\end{abstract}

Correspondence to: Dr Marcelo L. Rodriguez-Puebla, Department of Molecular Biomedical Sciences, The Center for Human Health and the Environment, and The Comparative Medicine Institute, North Carolina State University, CVM-MBS, 1060 William Moore Drive, Raleigh, NC 27607, USA

E-mail: mrodriguez@ncsu.edu

${ }^{*}$ Contributed equally

Abbreviations: HF, Hair-Follicle; SP, Side-Population; DMBA, 7,12-dimethylbenz[a]anthracene; TPA, 12-O-tetradecanoylphorbol13-acetate

Key words: keratinocytes, progenitors, hair-follicle, skin, epidermis

\section{Introduction}

A subset of cells, termed the side-population (SP), with characteristics of adult stem cells were discovered in hematopoietic tissue $(1,2)$. Similarly, other side-populations have been identified in tissues, tumors and cell lines (3-5). The main feature of these SPs is their high efflux capability of antimitotic drugs. This characteristic allows the isolation of the SP based on their capacity to efflux the Hoechst 33342 dye $(1,2)$. The membrane transporter breast-cancer-resistance-protein (BCRP1/ABCG2), which belongs to the multidrug resistance protein family, is responsible for the efflux of Hoechst 33342 (6). In agreement with their high efflux capacity, high expression of the BCRP1/ABCG2 was observed in the SP from hematopoietic lineage (7). Functional studies in the bone marrow, suggest that the ability to efflux Hoechst 33342 may represent a universal stem cell trait. Remarkably, the SP has characteristics of adult stem cells such as long-term repopulating capacity, undifferentiated phenotype, and colony forming potential $(1,2)$.

The skin is a multi-layered organ formed by the epidermis, dermis, hair follicles, sebaceous glands and subcutaneous tissue. In particular, the epidermis undergoes continual renewal, and their regenerative capacity is conferred by stem and progenitor cells located in the interfollicular epidermis and hair follicle (8-13). Other groups have previously investigated the existence of a SP in human and mouse epidermis (4,14-18). However, contradictories results have been reported in regard to their stem cell features, anatomic localization, and expression of surface markers. The discrepancies observed in the phenotype and behavior of epidermal SPs seem to be related to the cell isolation methodology, the Hoechst staining techniques and the anatomical origin of the epidermal cells. Numerous stem/progenitor cells have been localized in different regions of the skin such as in the interfollicular epidermis, sebaceous glands and hair follicle; however, whether any of these stem/progenitor cells behave as a side population is unknown. Herein, we present evidence demonstrating that a subset of cells expressing the MTS24/Plet1 surface marker can be isolated as a SP from the mouse hair follicle. These cells were located in the upper isthmus of the mouse hair follicle. 
Importantly, a follicular keratinocyte cell population with characteristics of progenitor cells was previously localized in this region of the hair follicle $(13,19)$. Consistent with their SP characteristics, we determined that these cells show elevated expression of the ABCG2 transporter and co-localizes with the MTS24 marker suggesting that the ABCG2 transporter can be used as a marker of the hair follicle SP. Moreover, this SP does not express CD34 and keratin 15 (K15) which are characteristic of the multipotent stem cells of the bulge region of the hair follicle (BuSCs).

Early reports have shown that BuSCs partially overlap with label-retaining cells (LRCs), previously described as tumor initiating cells $(8,20-22)$. However, it is not clear whether other hair-follicle progenitor cells play a role as skin tumor initiating cells. We sought to study whether the hair follicle $\mathrm{SP}$ is involved in skin tumor progression. We observed keratinocytes expressing MTS24 and the ABCG2 transporter on the proliferative basal cell layer of mouse skin papillomas. Importantly, immunostaining analysis of chemically induced skin tumors showed an increased number of cells expressing MTS24 and ABCG2 in malignant regions of mouse skin tumors. Furthermore, we established a direct correlation between the size of the SP and the rate of malignancy in tumor cell lines derived from mouse skin tumors, suggesting that the SP plays a role in malignant progression. Consistent with these results, the SPs have been identified in numerous cancer cell lines, as important contributors to tumor maintenance and tumorigenic potential (23-26). We conclude that ABCG $2^{+} / \mathrm{MTS}_{2} 4^{+}$cells identified a SP localized in the upper isthmus of the hair follicle. In addition, histopathological analysis of skin papillomas suggest that this SP may play a role in skin tumor progression.

\section{Materials and methods}

Mouse models. All animal experiments were approved by the NC State University Institutional Animal Care and Use Committee (IACUC). FVB/NCrl mice were obtained from Charles River laboratories (strain 207) and K15EGFP mice from The Jackson Laboratory (B6.Cg-Tg [Krt1-15-EGFP] 2Cot/J, Stock number 005244).

Skin papillomas were induced in transgenic mice overexpressing CDK4 in the epidermis (K5CDK4) by the two-stage carcinogenesis protocol as we previously described $(27,28)$. Briefly, groups of 20 mice each (K5CDK4 and wild type siblings) were initiated at day 1 after birth by topical application of $50 \mathrm{mg}$ of DMBA in $50 \mathrm{ml}$ of acetone on the mouse back. At day 14, mice received $2.5 \mathrm{mg}$ of TPA in $200 \mathrm{ml}$ of acetone twice a week for 20 weeks. Skin papillomas were collected at the end of the experiment at 30 weeks. Immunohistochemical analysis of skin tumors was performed on paraffin-embedded sections from mouse skin papillomas as described below.

Identification of side population. We used a method developed by Goodell et al for the identification of side population of mouse keratinocytes (2). Mouse keratinocytes from the hair follicle were isolated after disposal interfollicular keratinocytes as we previously reported (29). Briefly, dorsal skins from 7 -week old mice were pooled and disassociated into single cells by incubating in $0.25 \%$ trypsin for $5 \mathrm{~min}$ at $37^{\circ} \mathrm{C}$. Cells were washed and suspended at $1 \times 10^{6}$ cells $/ \mathrm{ml}$ in PBS with $2 \%$ fetal bovine serum and further incubated with Hoechst 33342 dye (Sigma, St. Louis) at $5 \mu \mathrm{g} / \mathrm{ml}$ with or without a $100 \mu \mathrm{M}$ verapamil for $90 \mathrm{~min}$ at $37^{\circ} \mathrm{C}$. Cells were centrifuged, washed, and suspended in PBS $/ 2 \%$ fetal bovine serum and $2 \mu \mathrm{g} / \mathrm{ml}$ of Propidium iodide (PI). Flow cytometric analysis was conducted using a DAKO Cytomation MoFlo Ultra-High Speed Cell Sorter. Hoechst dye was excited with a UV laser set at $350 \mathrm{~nm}$ and its fluorescence measured using a 450/20-nm (Hoechst blue) band-pass filter and a 670 filter (Hoechst red). Cells were analyzed and sorted within PI-negative cells, which represents a living population. The side-population gate was chosen by a direct comparison against the verapamil-treated cells. Three independent replication of this experiment confirms the percentage of SP in the mouse hair follicle.

CH72, JWF2, C50 and 308 cell lines were cultivated on EMEM (Cambrex, \#06-174 G) + 1\% chelex FBS, whereas $\mathrm{Balb} / \mathrm{MK} 2$ cells were incubated on $\mathrm{EMEM}+8 \%$ chelex FBS. Cells were suspended by trypsination, washed and suspended on PBS (without $\mathrm{Ca}^{2+}$ and $\mathrm{Mg}^{2+}$ ). Side population's analyses were conducted by FACS analysis as described for mouse keratinocytes.

Reverse transcription-PCR of SP and non-SP keratinocytes. SP and non-SP cells were sorted into microcentrifuge tubes, and total RNA extracted using a RNeasy Kit (Id 74134, Qiagen, Germantown, MD). Thirty ng of total RNA were used for first-strand cDNA synthesis in the reverse transcription-PCR (RT-PCR) mixture: $4 \mu \mathrm{l}$ of $5 \mathrm{X}$ first strand buffer, $1 \mu \mathrm{l}$ of $0.1 \mathrm{~mol} / \mathrm{L}$ DTT, $1 \mu \mathrm{l}$ of RNaseOUT RNase inhibitor, $1 \mu 1$ of random hexamer primers $(50 \mu \mathrm{m}), 1 \mu \mathrm{l}$ of $10 \mathrm{mmol} / \mathrm{l}$ deoxynucleotide triphosphate mix, and $1 \mu \mathrm{l}$ of SuperScript III reverse transcriptase and brought to $20 \mu \mathrm{l}$ with RNase-free water. The reverse transcriptase mixture was incubated at $65^{\circ} \mathrm{C}$ for $5 \mathrm{~min}$, $25^{\circ} \mathrm{C}$ for $5 \mathrm{~min}, 50^{\circ} \mathrm{C}$ for $60 \mathrm{~min}$, and $70^{\circ} \mathrm{C}$ for $15 \mathrm{~min}$. q-PCR was conducted using $1.5 \mu \mathrm{l}$ of the reverse transcription reaction and SYBR Green Supermix (Bio-Rad, Hercules, CA). The reference gene glyceraldehyde-3-phosphate dehydrogenase (GAPDH) was used to normalize the $\mathrm{Ct}$ values of the genes of interest $(\Delta \mathrm{Ct})$. Relative alterations (fold change) in mRNA expression levels in SP and non-SP were calculated according to the algorithms $2^{-(\Delta \Delta C t)}$. FACS isolation was performed in duplicate, and each qRT-PCR reaction was performed in triplicate. PRIMERS: CD34 (F: aggctctggaactccacacacttt, R: taa gcatatggctcggtgggtgat), $\alpha 6$ integrin (F: agcccagggacttacaact, R: ctcttggagcaccagacaca), ABCG2 (F: ccatagccacaggccaaa, R: gggccacatgattcttccac), Lrig1 (F: accatttcactccaggcaac, R: gtg aagatgcctacggtggt), Lgr6 (F: aggtgtcagaagctggagga, R: tcagct ggttgtcagtcagg), Keratin 15 [K15] (F: ggaggtggaagccgaagtat, R: gagaggagaccaccatcgcc), CD71 (F: tcgcttatattgggcagacc, R: ccatgtttgaccaatgctg), GAPDH (F: gcaaagtggacattgtcgccatca, R: tcctggaagatggtgatggccttt).

Immunostaining. Murine dorsal skins were embedded in OCT compound (Tissue-Tek; American Master Tech Scientific), frozen, and sectioned following standard protocols. Sections were blocked with $10 \%$ normal serum, and stained with antibodies for anti-CD34 (BD Biosciences, Pharmingen, San Jose, CA), anti-BCRP1/ABCG2 (ab24115, Abcam, Cambridge, MA) and anti-MTS24/Plet-1 (sc-240781, Santa Cruz Biotech.) 
followed by incubation with Alexafluor secondary antibodies (FITC re-conjugated anti-Rat or anti-goat; ThermoFisher, Molecular probes, Waltham, MA). Frozen cross-sections were counterstained with 4'6'-diamidino-2-phenylindole (DAPI) and visualized under a fluorescence microscope using a 465 to $495 \mathrm{~nm}$ filter. Paraffin-embedded sections from mouse skin papillomas were immunostained with anti-MTS24 and anti-ABCG2 antibodies described above. The number of MTS24+ and $\mathrm{ABCG} 2^{+}$cells were determined in sections of $250 \mu \mathrm{m}^{2}$ with a reticular grid.

Statistical analysis. Statistical analysis was performed using GraphPad Prism 4 Software (GraphPad Software, San Diego, CA, USA).

\section{Results}

Mouse hair follicles harbors a side-population of keratinocytes expressing the cell-surface marker MTS24. Numerous stem/progenitor cells have been localized in different regions of the mouse hair follicle $(9,13,30,31)$; however, whether any of these cells behave as a SP remains to be elucidated. Therefore, we first sought to localize and characterize a SP in the mouse hair follicle. Mouse keratinocytes from the hair follicle (HF-keratinocytes) were isolated after disposal of the interfollicular keratinocytes as we previously described (29).

HF-keratinocytes were incubated with Hoechst 33342 or Hoechst $33342+100 \mu \mathrm{M}$ verapamil. The addition of verapamil, which blocks the ABCG2 transporter, resulted in the reduction of the SP to background levels as determined via flow cytometry analysis (data not-shown) (29). We observed that $1.8 \%$ of the HF-keratinocytes actively effluxed the Hoechst 33342 dye and showed that $85 \%$ of the hair follicle SP were MTS24-positive (Fig. 1A and B). This outcome is consistent with a previous finding showing that a MTS24-positive progenitors located between the sebaceous glands and the hair follicle bulge (19). To further confirm the SP nature of the MTS24+ cells, we investigated the expression of the ABCG2 transporter. Real-time PCR analysis of the SP and non-SP fractions described in the fig. 1A revealed 2.5-fold elevated expression of the ABCG2 transporter in SP, supporting the high efflux of Hoechst 33342 by the SP fraction (Fig. 1C). Different populations of hair follicle stem/progenitors were characterized for the expression of surface markers such as CD34, MTS24, Lrg1, Lgr6, a6-integrin and keratin 15 (K15) (19,32-37). To establish the relationship of the hair follicle SP to the previously described stem/progenitors keratinocytes, we set out to determine the expression of the stem cell markers keratin 15, integrin $\alpha 6$ and the cell-surface markers CD34, Lrig1, Lgr6, CD71 via qRT-PCR. We observed a reduced level of CD34 and keratin 15 in the SP confirming that these cells are different from the $\mathrm{CD} 34^{+} / \mathrm{K} 15^{+}$multipotent stem cells localized in the bulge region of the hair follicle $(15,19,34)$. Moreover, we determine that the expression level of Lrig1 and Lgr6 markers, which define progenitor cell populations restricted to the junctional zone (35) and the central isthmus of the hair follicle (36), was also low in the SP (Fig. 1C). We conclude that the hair follicle SP is composed of MTS24-positive progenitors, which are different from the Lrg1-, Lgr6- and CD34-positive stem/progenitors cells.
Similar levels of expression of the integrin $\alpha 6$ confirm the keratinocyte nature of both, SP and non-SP.

To further elucidate whether the hair follicle SP is restricted to a specific area of the hair follicle, we performed immunofluorescence analysis to localize the ABCG2 and MTS24 proteins in the mouse hair follicle (Fig. 2). We utilized the dorsal skin from 7-weeks old K15-EGFP transgenic mice, which expresses the green fluorescent protein (EGFP) under the control of the keratin 15 promoter in the bulge area of the hair follicle (32). Bright staining of MTS24 was predominantly found within a region between the bulge and the sebaceous gland (Fig. 2A and E). Notably, this region was also positive for the ABCG2 transporter (Fig. 2F). Overlapping image of MTS24 and ABCG2 immunofluorescence showed that both proteins are express in the upper isthmus of the hair follicle (Fig. 2G, yellow color). These results are consistent with the previous localization of MTS24+ keratinocytes (19). EGFP staining labeled keratinocytes expressing $\mathrm{K} 15$ in the bulge area of the hair follicle (Fig. 2B). Overlapping image of MTS24 and EGFP immunostaining confirm that the hair follicle side-population and $\mathrm{K} 15 / \mathrm{CD} 34^{+}$cells are different stem/progenitor cells (Fig. 2C).

Increase size of epidermal side-populations skin tumor and tumor cell lines. Consistent with the high efflux capability to Hoechst 33342, the ABCG2 transporter has been identified as a candidate protein responsible for cancer multidrug resistance. In fact, the ABCG2 gene encodes the breast cancer resistance protein (BCRP1) which is expressed in colon, breast, stomach and fibrosarcoma cell lines $(38,39)$. This data suggests that the tumor SPs play an important role in tumor resistance to chemotherapeutic treatments. Importantly, the SP has been found on numerous cancer cell lines, and cells derived from primary tumors $(23,25,26)$. Herein, we studied the presence of the SP in skin tumor cell lines. We utilized a set of cell lines derived from mouse skin keratinocytes (C50 and Balb/MK2), chemically initiated skin keratinocytes [308 cell line, (40)], and squamous-cell carcinomas (SCC) [JWF2 and $\mathrm{CH} 72$, (41,42)]. Therefore, this model allows direct comparison between the SPs isolated from different stages of tumor progression. We evaluated the percentage of SP in each cell line by Hoechst 33342 dye exclusion. Incubation of each cell line in the presence of verapamil resulted in limited detection of the SP to a background level, indicating that dye efflux occurs through the ABC transporters. We use verapamil treatment as a mean to define the presence of the SPs. Cell cultures from non-tumorigenic keratinocytes (C50, Balb/Mk2) and cells derived from initiated skin (308) showed a low rate of SP. The percentage of cells isolated as SPs in the Balb/Mk2 $(0.1 \%), \mathrm{C} 50(0.2 \%)$ and $308(0.3 \%)$ cell lines were similar to the percentage originally observed in the hematopoietic system (1). In contrast, we detected an increased percentage of SPs in the JWF2 (4.7\%) and CH72 (4.3\%) cell lines, which showed 15-fold rise in the number of SP cells compared with the 308 cells (t-test, $\mathrm{P}<0.0001$ ) (Fig. 3). Our results show a direct correlation between the increase number of progenitor/stem cells determined by the SP technique and the ability of these cells to drive malignant progression in mouse epidermis. To the best of our knowledge, this is the first time that a direct comparison between SPs was performed on cell lines derived from different stages of the tumor progression. 

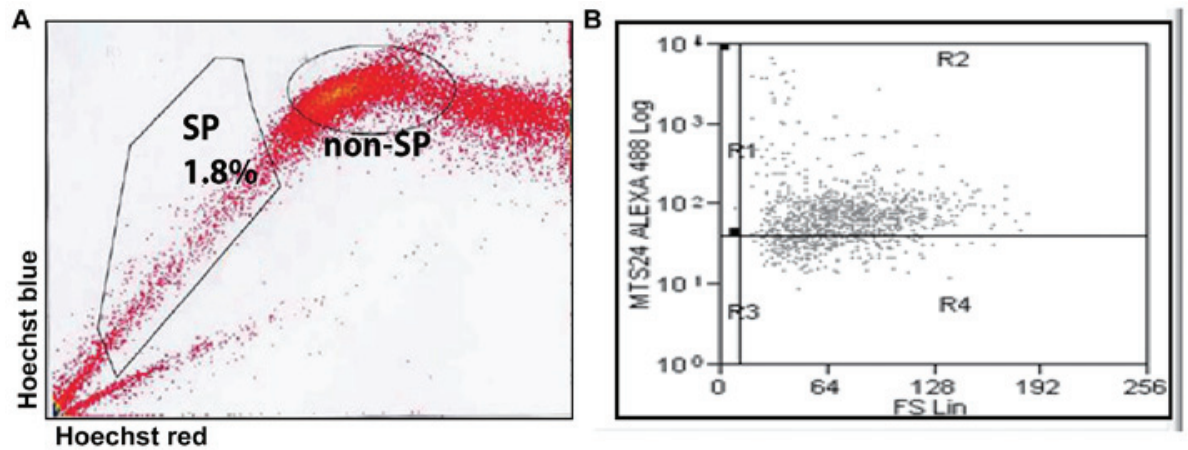

\begin{tabular}{|c|c|}
\hline Cenes & SP / non-SP \\
\hline CD34 & 0.31 \\
\hline$\alpha 6$ & 0.90 \\
\hline ABCG2 & 2.47 \\
\hline K15 & 0.01 \\
\hline CD71 & 0.85 \\
\hline Lrig1 & 0.21 \\
\hline Lgr6 & 0.388 \\
\hline
\end{tabular}

Figure 1. The side-population from the mouse hair follicle. (A) Hoechst 33342 staining of the mouse hair follicle epidermal cell suspension reveals that $1.8 \%$ of total HF keratinocytes excluded Hoechst and was defined as a SP. Three independent replication of this experiment confirms the percentage of SP in the mouse hair follicle. (B) Staining with anti-MTS24/Plet1 antibody shows that 85\% of the SP express the MTS24 surface marker. (C) Expression of hair follicle stem/progenitor markers was determined by qRT-PCR. $2^{-\Delta \Delta C T}$ values from SP and non-SP were quantified with specific primers for CD34, $\alpha 6$ integrin ABCG2/BCRP1, LRIG1, Lgr6, keratin 15 (K15), and CD71. The reference gene GAPDH was used to normalize the Ct value of the genes of interest. The cell fraction enriched in each marker was calculated as the ratio of SP/non-SP. Values $>1$ represents higher expression in SP, whereas values $<1$, represent a higher expression in non-SP.
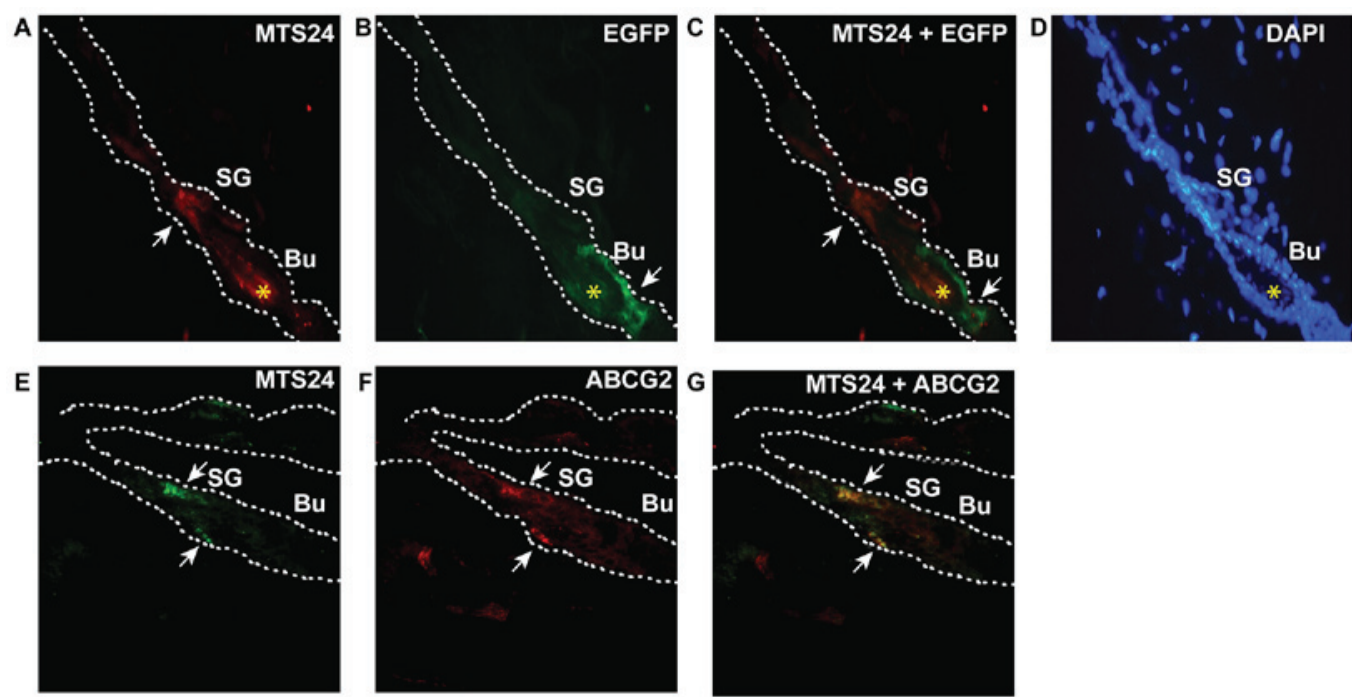

Figure 2. Expression of ABCG2 transporter and MTS24 surface marker in the mouse hair follicle (HF). Dorsal skin cryosections were labeled with antibodies against (A and E) the cell surface marker MTS24 (arrows) and (F) the ABCG2 transporter (arrows). (B) Enhance green fluorescent protein (EGFP) show cells expressing the keratin 15 (K15) in the transgenic mice K15EGFP (arrow). (C) Overlapping immunofluorescence of panels A and B reveals that MTS24 does no colocalize with the HF bulge marker K15, (G) whereas overlapping image of panels E and F shows that MTS24 and ABCG2 colocalize in the isthmus area of the HF. SG, sebaceous gland; Bu, bulge region of the HF; "Auto fluorescence (hair shaft). DAPI counter stain (D).

To determine whether the increase percentage of the SPs observed in keratinocyte cell lines denote what occur during mouse skin carcinogenesis, we examine a series of chemically initiated mouse skin papilloma. We evaluated tumor cells expressing the ABCG2 transporter and the cell surface marker MTS24 on mouse skin papillomas in which transgenic expression of the cyclin dependent kinase 4 in the skin (K5CDK4 transgenic mice) resulted in early premalignant changes $(27,43)$. The ABCG2 transporter and MTS24 surface marker were expressed in clusters of cells on the proliferative basal cell layer of skin papillomas (Fig. 4). Skin papillomas from transgenic K5CDK4 mice at 30 weeks of promotion, presented areas of marked atypia and lack of differentiation pattern (intra-papilloma carcinoma and carcinoma in situ) (27). Remarkable, we observed an increased number of cells expressing ABCG2 and MTS24 in papillomas 

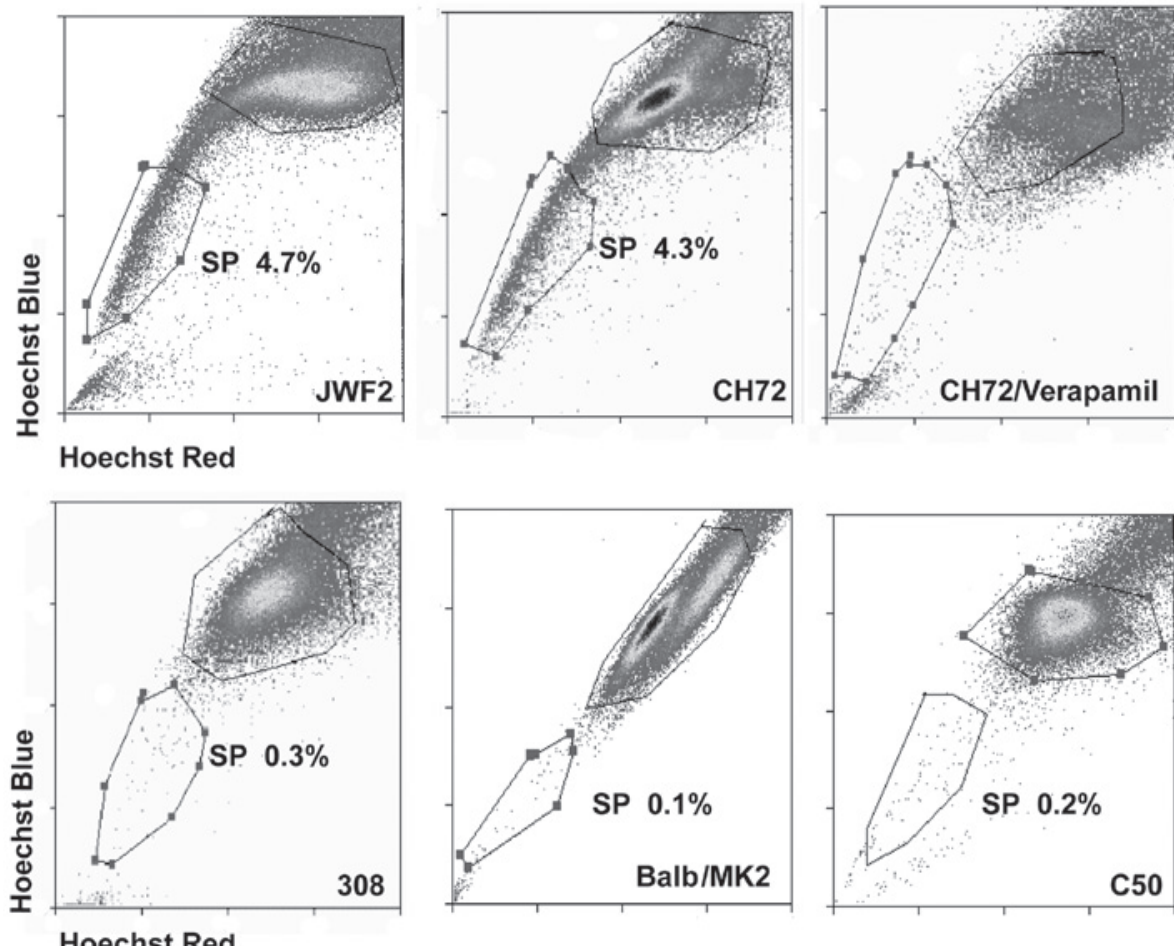

Figure 3. Detection of side population (SP) in mouse epidermal cell lines. Hoechst 33342 staining of mouse cell lines reveals that a low number of SP cells in the epidermal cell lines Balb/MK2 (0.1\%) and C50 (0.2\%), and the papilloma cell line $308(0.3 \%)$. A higher number of cells derived from the mouse epidermal squamous cell carcinomas showed the SP patter of staining (JWF2, 4.7\%; and CH72, 4.3\%) compared to epidermal cell lines (t-test, P<0.0001). Verapamil treatment was used to determine the gated region of each cell lines. Example, $\mathrm{CH} 72 /$ verapamil.

of the K5CDK4 transgenic mouse. Whereas wild-type tumors showed 12 cells per clusters expressing ABCG2 and MTS24, papillomas from K5CDK4 transgenic mice showed $\sim 50$ cells per clusters expressing the SP markers $(\mathrm{P}<0.05$, t-test $)$ (Fig. 4E). Altogether, these results suggest that the increased size of the SP may play a functional role during the skin tumor progression or, alternatively, the increased number of SP cells may contribute to the maintenance of the malignant phenotype (44-46).

\section{Discussion}

The existence of SP has been determined in many tumors and tissues, including the epidermis. However, the functional role of epidermal SP remains ambiguous. Some early investigations suggested that the SP in mouse epidermis lacks the stem cell characteristics $(16,47,48)$, whereas other groups reported opposite results $(4,15)$. For instance, it has been suggested that the mouse epidermal SPs lack the stem cell features, because the majority of the label-retaining cells, which are considered multipotent stem cells, are found in the non-SP fraction (47). On contrary, it was reported that epidermal SPs behave as keratinocyte stem cells due of their higher expression of the $\beta 1$, $\alpha 6$ integrins (4) exhibiting phenotypic and functional features of stem cells (15). These discrepancies might be due to cell isolation methodology or more importantly to the cellular origin of the SPs.

Here, we described a SP isolated from the mouse hair follicle which is restricted to the upper isthmus, a region between the sebaceous gland and the bulge. These cells express the ABCG2 transporter, which supports its SP characteristics, and the MTS24 surface marker. Supporting a stem/progenitor role of this SP, Jensen et al described a keratinocyte population with characteristics of progenitors in the upper isthmus of the mouse HF (13). Other groups have reported the localization of a SP in the interfollicular region of the mouse epidermis. In agreement with the description of the HF side-population, the interfollicular SPs of newborn and adult mice also showed an elevated expression of the ABCG2 transporter (4). Likely, the inconsistency in terms of the localization of the epidermal SP is due to cell isolation methodology. In fact, we isolated a SP from the mouse hair follicle, after disposal the interfollicular keratinocytes, whereas Yano et al make use of a full epidermal preparation $(4,29)$. Therefore, it is possible that distinct SP may exist in different regions of the mouse epidermis or alternatively, the hair follicle SP may give origin to the interfollicular SP. We utilized the epidermis of 7-days old mice in which the HF is in the rest phase of the hair cycle (telogen), but an observation generated during the course of this study shows that induction of anagen (proliferative phase of hair follicle cycle) by topical application of TPA result in detection of the MTS24+ cells in the interfollicular epidermis (unpublished data). Similarly, Trempus et al showed that MTS2 $4^{+}$cells are located in the interfollicular epidermis after topical treatment with TPA (34). Although, lineage studies are necessary to define the relationship between hair follicle and interfollicular SPs, we cannot rule out the possibility that the hair follicle SP might give origin to the interfollicular SP in specific phases of the hair cycle or in pathologic conditions leading to mobilization of the HF keratinocytes to the interfollicular epidermis. This model is supported for a recent publication showing that $\mathrm{ABCG} 2$ deficiency in skin impairs re-epithelialization in cutaneous wound-healing (49). 

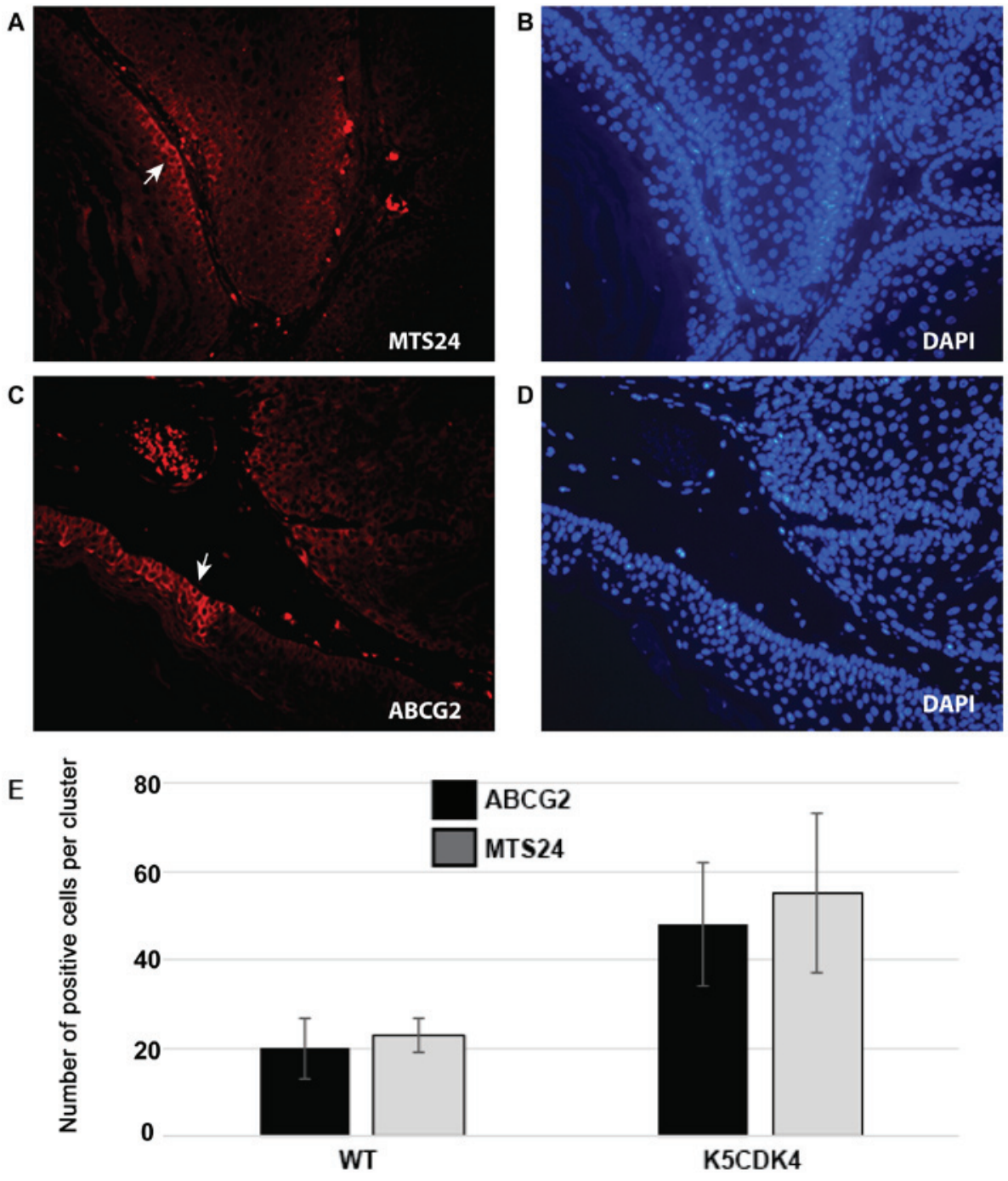

Figure 4. Immunofluorescence analysis of MTS24 and ABCG2 in skin papillomas. (A and C) Expression of the ABCG2 transporter and the MTS24 surface marker was detected in the basal cell layer of skin papillomas (arrows). (B and D) DAPI counter stain. (E) Increase number of ABCG2 ${ }^{+}$and MTS24 ${ }^{+}$cells were observed in premalignant areas of K5CDK4 papillomas compared to wild-type (WT) tumors $(\mathrm{P}<0.05$, t-test).

Therefore, it is conceivable that the ABCG2-positive SP plays an active role as progenitors during epidermal regeneration. Hence, the functional role of the hair follicle SP as progenitors of interfollicular epidermis warrant future investigations.

Notably, the anatomical localization of the epidermis might also influence the SP characteristics since SPs isolated from tail skin seem to be part of the transit amplifying, but not the progenitor compartment (47). On contrary, the hair follicle SP is composed by $\mathrm{ABCG} 2^{+} / \mathrm{MTS}_{2} 4^{+}$cells, with characteristics of progenitor cells (19); although, they are different from the $\mathrm{CD} 34^{+}$bulge stem cells and the $\mathrm{Lrig} 1^{+}$and $\mathrm{Lgr} 6^{+}$progenitors. It worth mentioning that the MTS2 $4^{+}$keratinocytes are a heterogeneous population composed for cells with a variable amount of the integrin $\alpha 6$ ( $\alpha 6$-low and $\alpha 6$-high) (13). Therefore, it remains to be determined whether both, $\alpha 6$-low and $\alpha 6$-high, keratinocytes form part of the SP. Moreover, our studies have shown that $85 \%$ of the SP express the MTS24 marker, leave open the possibility that MTS24-negative cells can also efflux Hoeschst 33342 and behave as a SP.

Pioneer studies have established that the interfollicular and hair follicle bulge stem cells are carcinogen targets that give rise to latent neoplastic cells contributing to tumor development (50-52). In agreement, it has been recently recognized that $\mathrm{K} 15^{+}$stem cells contribute to skin papilloma development (37). However, whether other hair follicle progenitor cells also contribute to tumor initiation need to be determined. In this regard, it is now known that HFs are home to many populations with stem cell properties, each with different markers and different locations within the follicle. Here, we have shown that similar to $\mathrm{K} 5^{+} / \mathrm{CD} 34^{+}$bulge stem cells, $\mathrm{ABCG} 2^{+} / \mathrm{MTS}^{2} 4^{+}$cells are located in specific areas of the mouse skin papillomas. In addition, we observed an increase number of $\mathrm{ABCG} 2^{+} / \mathrm{MTS}_{2} 4^{+}$ keratinocytes in premalignant skin papillomas suggesting that the epidermal tumor SPs might be composed for cancer stem cells (CSCs). This effect is different from the one reported for $\mathrm{K} 15^{+}$bulge stem cells which contribution to skin tumors does not appear to increase during the malignant progression (37). The concept of CSCs has generated much hope for cancer treatment because are thought that CSCs are resistant to chemotherapy and molecular therapies via their high expression of the multidrug resistance genes (53). Therefore, our data suggest that the epidermal tumor cells expressing ABCG2 and MTS24 may 
play an important role in tumor resistance to chemotherapeutic treatments. Therefore, identification of skin stem/progenitors cells such as the $\mathrm{ABCG} 2^{+}$cells will allow studying their specific role in tumor promotion and progression in cutaneous squamous cell carcinomas. Although the best of our knowledge a similar SP has not been characterized in human SCCs, utilizing the drug high efflux features of keratinocyte SP to isolated $\mathrm{ABCG}^{+}$ cells in human SCC will allow to study their tumor resistance to chemotherapeutic treatments. This is especially important in high-risk squamous cell carcinomas which represent a subgroup of this disease, where patients are at higher risk of metastasis and death (54). Moreover, isolation of stem/progenitor cells is of paramount importance as a source of epidermal renewal in vivo. We expect that future identification of the regulatory sequences of MTS24/Plet1 and ABCG2 genes will allow employ transgenic mouse technology to trace in intact follicles the lineage of the side population into differentiated epithelia and skin tumors.

\section{Acknowledgements}

The authors thank Ms. Rima Majumdar (North Carolina State University, College of Veterinary Medicine, Raleigh, NC, USA) for her technical support, the Laboratory Animal Resources, the Flow Cytometry and Cell Sorting Laboratory and the Histology Core at the College of Veterinary Medicine, North Carolina State University for helping with the processing and staining of skin and tumor samples. The present study was supported by NIEHS (award no. P30ES025128) Center for Human Health and the Environment. Research reported in this publication was supported by NCI grant RO1CA116328 and NIEHS under award number P30ES025128 Center for Human Health and the Environment.

\section{References}

1. Goodell MA, Brose K, Paradis G, Conner AS and Mulligan RC: Isolation and functional properties of murine hematopoietic stem cells that are replicating in vivo. J Exp Med 183: 1797-1806, 1996.

2. Goodell MA, McKinney-Freeman S and Camargo FD: Isolation and characterization of side population cells. Methods Mol Biol 290: 343-352, 2005.

3. Shimano K, Satake M, Okaya A, Kitanaka J, Kitanaka N, Takemura M, Sakagami M, Terada N and Tsujimura T: Hepatic oval cells have the side population phenotype defined by expression of ATP-binding cassette transporter ABCG2/BCRP1. Am J Pathol 163: 3-9, 2003.

4. Yano S, Ito Y, Fujimoto M, Hamazaki TS, Tamaki K and Okochi H: Characterization and localization of side population cells in mouse skin. Stem Cells 23: 834-841, 2005.

5. Challen GA and Little MH: A side order of stem cells: The SP phenotype. Stem Cells 24: 3-12, 2006.

6. Zhou S, Schuetz JD, Bunting KD, Colapietro AM, Sampath J, Morris JJ, Lagutina I, Grosveld GC, Osawa M, Nakauchi H and Sorrentino BP: The ABC transporter Bcrp1/ABCG2 is expressed in a wide variety of stem cells and is a molecular determinant of the side-population phenotype. Nat Med 7: 1028-1034, 2001.

7. Kim M, Turnquist H, Jackson J, Sgagias M, Yan Y, Gong M, Dean M, Sharp JG and Cowan K: The multidrug resistance transporter ABCG2 (breast cancer resistance protein 1) effluxes Hoechst 33342 and is overexpressed in hematopoietic stem cells Clin Cancer Res 8: 22-28, 2002.

8. Cotsarelis G, Sun TT and Lavker RM: Label-retaining cells reside in the bulge area of pilosebaceous unit: Implications for follicular stem cells, hair cycle, and skin carcinogenesis. Cell 61: 1329-1337, 1990.

9. Fuchs E, Tumbar T and Guasch G: Socializing with the neighbors: Stem cells and their niche. Cell 116: 769-778, 2004.
10. Lavker RM and Sun TT: Epidermal stem cells: Properties, markers, and location. Proc Natl Acad Sci USA 97: 13473-13475, 2000.

11. Watt FM: Epidermal stem cells: Markers, patterning and the control of stem cell fate. Philos Trans R Soc Lond B Biol Sci 353: 831-837, 1998.

12. Horsley V, O'Carroll D, Tooze R, Ohinata Y, Saitou M, Obukhanych T, Nussenzweig M, Tarakhovsky A and Fuchs E: Blimp1 defines a progenitor population that governs cellular input to the sebaceous gland. Cell 126: 597-609, 2006.

13. Jensen UB, Yan X, Triel C, Woo SH, Christensen R and Owens DM: A distinct population of clonogenic and multipotent murine follicular keratinocytes residing in the upper isthmus. J Cell Sci 121: 609-617, 2008

14. Montanaro F, Liadaki K, Volinski J, Flint A and Kunkel LM: Skeletal muscle engraftment potential of adult mouse skin side population cells. Proc Natl Acad Sci USA 100: 9336-9341, 2003.

15. Redvers RP, Li A and Kaur P: Side population in adult murine epidermis exhibits phenotypic and functional characteristics of keratinocyte stem cells. Proc Natl Acad Sci USA 103: 13168-13173, 2006.

16. Terunuma A, Jackson KL, Kapoor V, Telford WG and Vogel JC: Side population keratinocytes resembling bone marrow side population stem cells are distinct from label-retaining keratinocyte stem cells. J Invest Dermatol 121: 1095-1103, 2003.

17. Kaur P and Li A: Adhesive properties of human basal epidermal cells: An analysis of keratinocyte stem cells, transit amplifying cells, and postmitotic differentiating cells. J Invest Dermatol 114: 413-420, 2000

18. Macias E, Miliani de Marval PL, Senderowicz A, Cullen J and Rodriguez-Puebla ML: Expression of CDK4 or CDK2 in mouse oral cavity is retained in adult pituitary with distinct effects on tumorigenesis. Cancer Res 68: 162-171, 2008.

19. Nijhof JG, Braun KM, Giangreco A, van Pelt C, Kawamoto $H$, Boyd RL, Willemze R, Mullenders LH, Watt FM, de Gruijl FR and van Ewijk W: The cell-surface marker MTS24 identifies a novel population of follicular keratinocytes with characteristics of progenitor cells. Development 133: 3027-3037, 2006.

20. Morris RJ, Fischer SM and Slaga TJ: Evidence that a slowly cycling subpopulation of adult murine epidermal cells retains carcinogen. Cancer Res 46: 3061-3066, 1986.

21. Morris RJ and Potten CS: Highly persistent label-retaining cells in the hair follicles of mice and their fate following induction of anagen. J Invest Dermatol 112: 470-475, 1999.

22. Morris RJ: Keratinocyte stem cells: Targets for cutaneous carcinogens. J Clin Invest 106: 3-8, 2000.

23. Kondo T, Setoguchi T and Taga T: Persistence of a small subpopulation of cancer stem-like cells in the C6 glioma cell line. Proc Natl Acad Sci USA 101: 781-786, 2004.

24. Patrawala L, Calhoun T, Schneider-Broussard R, Zhou J, Claypool K and Tang DG: Side population is enriched in tumorigenic, stem-like cancer cells, whereas ABCG2+ and ABCG2-A cancer cells are similarly tumorigenic. Cancer Res 65: 6207-6219, 2005.

25. Szotek PP, Pieretti-Vanmarcke R, Masiakos PT, Dinulescu DM, Connolly D, Foster R, Dombkowski D, Preffer F, Maclaughlin DT and Donahoe PK: Ovarian cancer side population defines cells with stem cell-like characteristics and mullerian inhibiting substance responsiveness. Proc Natl Acad Sci USA 103: 11154-11159, 2006.

26. Ho MM, Ng AV, Lam S and Hung JY: Side population in human lung cancer cell lines and tumors is enriched with stem-like cancer cells. Cancer Res 67: 4827-4833, 2007.

27. Miliani de Marval PL, Macias E, Conti CJ and Rodriguez-Puebla ML: Enhanced malignant tumorigenesis in Cdk4 transgenic mice. Oncogene 23: 1863-1873, 2004.

28. Robles AI, Rodriguez-Puebla ML, Glick AB, Trempus C, Hansen L, Sicinski P, Tennant RW, Weinberg RA, Yuspa SH and Conti CJ: Reduced skin tumor development in cyclin D1-deficient mice highlights the oncogenic ras pathway in vivo. Genes Dev 12: 2469-2474, 1998.

29. Miliani de Marval PL, Kim SH and Rodriguez-Puebla ML: Isolation and characterization of a stem cell side-population from mouse hair follicles. Methods Mol Biol 1195: 259-268, 2014.

30. Owens DM and Watt FM: Contribution of stem cells and differentiated cells to epidermal tumours. Nat Rev Cancer 3: 444-451, 2003.

31. Cotsarelis G: Epithelial stem cells: A folliculocentric view. J Invest Dermatol 126: 1459-1468, 2006. 
32. Liu Y, Lyle S, Yang Z and Cotsarelis G: Keratin 15 promoter targets putative epithelial stem cells in the hair follicle bulge. J Invest Dermatol 121: 963-968, 2003.

33. Trempus CS, Morris RJ, Bortner CD, Cotsarelis G, Faircloth RS, Reece JM and Tennant RW: Enrichment for living murine keratinocytes from the hair follicle bulge with the cell surface marker CD34. J Invest Dermatol 120: 501-511, 2003.

34. Trempus CS, Morris RJ, Ehinger M, Elmore A, Bortner CD, Ito M, Cotsarelis G, Nijhof JG, Peckham J, Flagler N, et al: CD34 expression by hair follicle stem cells is required for skin tumor development in mice. Cancer Res 67: 4173-4181, 2007.

35. Jensen KB, Collins CA, Nascimento E, Tan DW, Frye M, Itami S and Watt FM: Lrig1 expression defines a distinct multipotent stem cell population in mammalian epidermis. Cell Stem Cell 4: 427-439, 2009

36. Snippert HJ, Haegebarth A, Kasper M, Jaks V, van Es JH, Barker N, van de Wetering M, van den Born M, Begthel H, Vries RG, et al: Lgr6 marks stem cells in the hair follicle that generate all cell lineages of the skin. Science 327: 1385-1389, 2010.

37. Li S, Park H, Trempus CS, Gordon D, Liu Y, Cotsarelis G and Morris RJ: A keratin 15 containing stem cell population from the hair follicle contributes to squamous papilloma development in the mouse. Mol Carcinog 52: 751-759, 2013.

38. Doyle LA, Yang W, Abruzzo LV, Krogmann T, Gao Y, Rishi AK and Ross DD: A multidrug resistance transporter from human MCF-7 breast cancer cells. Proc Natl Acad Sci USA 95: 15665-15670, 1998.

39. Doyle L and Ross DD: Multidrug resistance mediated by the breast cancer resistance protein BCRP (ABCG2). Oncogene 22 7340-7358, 2003.

40. Kuletz-Martin M, Kilkenny AE, Holbrook KA, Digernes V and Yuspa SH: Properties of Carcinogen altered mouse epidermal cells resistant to calcium-induced terminal differentiation. Carcinogenesis 4: 1367-1377, 1983.

41. Ruggeri B, Caamano J, Goodrow T, DiRado M, Bianchi A Trono D, Conti CJ and Klein-Szanto AJ: Alterations of the p53 tumor suppressor gene during mouse skin tumor progression. Cancer Res 51: 6615-6621, 1991.
42. Conti CJ, Fries JW, Viaje A, Miller DR, Morris R and Slaga TJ: In vivo behavior of murine epidermal cell lines derived from initiated and noninitiated skin. Cancer Res 48: 435-439, 1988.

43. Macias E, Kim Y, Miliani de Marval PL, Klein-Szanto A and Rodriguez-Puebla ML: Cdk2 deficiency decreases ras/CDK4-dependent malignant progression, but not myc-induced tumorigenesis. Cancer Res 67: 9713-9720, 2007.

44. Reya T, Morrison SJ, Clarke MF and Weissman IL: Stem cells, cancer, and cancer stem cells. Nature 414: 105-111, 2001.

45. Pardal R, Clarke MF and Morrison SJ: Applying the principles of stem-cell biology to cancer. Nat Rev Cancer 3: 895-902, 2003.

46. Beachy PA, Karhadkar SS and Berman DM: Tissue repair and stem cell renewal in carcinogenesis. Nature 432: 324-331, 2004.

47. Triel C, Vestergaard ME, Bolund L, Jensen TG and Jensen UB: Side population cells in human and mouse epidermis lack stem cell characteristics. Exp Cell Res 295: 79-90, 2004.

48. Terunuma A, Kapoor V, Yee C, Telford WG, Udey MC and Vogel JC: Stem cell activity of human side population and alpha6 integrin-bright keratinocytes defined by a quantitative in vivo assay. Stem Cells 25: 664-669, 2007.

49. Chang HM, Huang WY, Lin SJ, Huang WC, Shen CR, Mao WY and Shen CN: ABCG2 deficiency in skin impairs re-epithelialization in cutaneous wound healing. Exp Dermatol 25: 355-361, 2016.

50. Morris RJ, Tryson KA and Wu KQ: Evidence that the epidermal targets of carcinogen action are found in the interfollicular epidermis of infundibulum as well as in the hair follicles. Cancer Res 60: 226-229, 2000.

51. Argyris TS: Tumor promotion by abrasion induced epidermal hyperplasia in the skin of mice. J Invest Dermatol 75: 360-362, 1980.

52. Argyris TS and Slaga TJ: Promotion of carcinomas by repeated abrasion in initiated skin of mice. Cancer Res 41: 5193-5195, 1981.

53. Dean M, Fojo T and Bates S: Tumour stem cells and drug resistance. Nat Rev Cancer 5: 275-284, 2005.

54. Jennings L and Schmults CD: Management of high-risk cutaneous squamous cell carcinoma. J Clin Aesthet Dermatol 3: 39-48, 2010. 